\title{
Evidence Suggesting the Beneficial use of Magnesium in Cerebral Ischaemia in an Experimental Model of Cardiac Arrest
}

\author{
Vassiliki Prapa, Theodoros Xanthos*, Eleni Koudouna, Eleni Bassiakou, Ismene Dontas, Despina \\ Perrea and Lila Papadimitriou
}

Department of Experimental Surgery and Surgical Research, 15B Agiou Thoma Street, 11527, Athens Greece

\begin{abstract}
Introduction: Brain damage is one of the major causes of morbidity and mortality in cardiac arrest victims. The aim of the present study was to determine whether administration of magnesium during cardiopulmonary resuscitation would improve post-resuscitation cerebral injury, as indicated by cerebral ischaemia markers and neurological alertness score.

Methods: Ventricular fibrillation was induced in 24 piglets, left untreated for $5 \mathrm{~min}$ before attempting resuscitation. Animals were randomised into 2 groups to receive saline as placebo + adrenaline (Group A) or magnesium sulphate + adrenaline (Group B) during cardiopulmonary resuscitation. Blood samples were collected in the post-resuscitation phase to measure NSE and S-100. Neurological alertness score was assessed 48h after the return of spontaneous circulation.

Results: S-100 and NSE values increased significantly in all resuscitated animals in the observation phase. However, S100 and NSE values in Group B were statistically lower than those measured in Group A during the whole postresuscitation period. Neurological outcome was better in Group B animals.

Conclusion: Magnesium may exert neuroprotective effects in cerebral ischaemia, caused by experimental cardiac arrest.
\end{abstract}

Keywords: Ventricular fibrillation, magnesium, NSE, S-100, neurological outcome.

\section{INTRODUCTION}

Cardiac arrest (CA) is responsible for 700,000 deaths per year in Europe [1]. Brain damage is one of the major causes of morbidity and mortality in CA victims. The cessation of cerebral perfusion after CA leads to global hypoxicischaemic brain damage due to death of neuronal and glia cells and loss of the integrity of the blood-brain barrier.

During recent years, great attention has been given to the levels of two molecular factors: neuron-specific enolase (NSE), and a protein soluble in $100 \%$ ammonium sulphate (S-100). These molecular factors correlate with neurological outcome of CA victims [2].

Magnesium has been shown to cause central arteriolar vasodilation and to act against vasospasm in the central nervous system [3]. This effect could be therapeutic against the no-flow phenomenon, often encountered in CA victims [4]. The aim of the present study was to determine whether administration of magnesium during cardiopulmonary resuscitation (CPR) would improve post-resuscitation cerebral injury, as indicated by brain ischaemia markers and by a neurological alertness score.

\section{MATERIALS AND METHODOLOGY}

The experimental protocol was approved by the General Directorate of Veterinary Services (permit no 445/14-12005). Twenty four piglets (Landrace/Large White) of both

*Address correspondence to this author at the Department of Experimental Surgery and Surgical Research, 15B Agiou Thoma Street, 11527, Athens Greece; E-mail: theodorosxanthos@yahoo.com sexes were included in this study. The experimental protocol has already been described [5].

Briefly, the animals were premedicated with the use of intramuscular injection of $10 \mathrm{mg} / \mathrm{kg}$ ketamine hydrochloride, $0.5 \mathrm{mg} / \mathrm{kg}$ midazolam, and $0.05 \mathrm{mg} / \mathrm{kg}$ atropine sulphate. Anaesthesia was induced with an intravenous bolus dose of propofol $(2.0 \mathrm{mg} / \mathrm{kg})$. While the pigs were breathing spontaneously, they were intubated with a 4.5 endotracheal tube. Additional $1 \mathrm{mg} / \mathrm{kg}$ propofol, $0.15 \mathrm{mg} / \mathrm{kg}$ cis-atracurium and $4 \mu \mathrm{g} / \mathrm{kg}$ fentanyl were administrated afterwards. The animals were then connected to the automatic volume-controlled ventilator (ventiPac Sims pneuPac, Greece) with $21 \%$ Oxygen $\left(\mathrm{FiO}_{2} 21 \%\right)$. End-tidal $\mathrm{CO}_{2}$ was monitored with a sidestream infrared $\mathrm{CO}_{2}$ analyzer (Nihon Kohden Corp). The respiratory frequency was adjusted to maintain $\mathrm{PETCO}_{2} 35$ $40 \mathrm{mmHg}$. Propofol and cis-atracurium were administered to maintain adequate anaesthetic depth. Fentanyl was administered when the cardiac rate was more than $120 \mathrm{bpm}$ and/or the systolic blood pressure over $130 \mathrm{mmHg}$.

Electrocardiographic monitoring (ECG) (Mennen Medical, Envoy, Greece) and pulse oximetry $\left(\mathrm{SpO}_{2}\right)(\mathrm{Vet} / \mathrm{Ox}$ Plus 4700 , Greece) were performed as previously described [6]. In order to detect changes in cerebral oxygenation, near infrared spectroscopy (NIRS) was utilised (Somanetics INVOS Cerebral Oximeter, Model SPFB Paediatric Somasensor SOMANETICS). The optodes of NIRS were mounted on the intact skin covering each cerebral hemisphere. For optimal spatial resolution, the interoptode distance was set to $5 \mathrm{~cm}$. Data was recorded every 10 seconds after induction of anaesthesia and for the duration of CA and resuscitation. The de- 
vice calculated the regional cerebral oxygen saturation $\left(\mathrm{rSO}_{2}\right)$.

The right common carotid artery was surgically prepared and dissected. Afterwards, a fluid-filled (model 6523, USCI $\mathrm{CR}$, Bart Inc, Greece) arterial catheter was inserted into the aorta for measurement of the aortic pressure. Mean arterial pressure (MAP) was determined electronically. When the right internal jugular vein was surgically prepared, a SwanGanz catheter (Opticath 5.5 F, $75 \mathrm{~cm}$ Abbott, Ethicon Mersilk ${ }^{\mathrm{TM}}$, Greece) was inserted into the right atrium and right atrial pressure was measured continuously. Coronary perfusion pressure (CPP) was electronically calculated as the difference between minimal aortic diastolic pressure and the simultaneously measured right atrial diastolic pressure. The left internal jugular vein was also surgically prepared in order to advance a $5 \mathrm{~F}$ flow-directed pacing catheter $\left(\mathrm{Pacel}^{\mathrm{TM}}\right.$; $100 \mathrm{~cm}$, St. Jude Medical, Greece) into the apex of the right ventricle.

The animals were randomized into two groups with the use of a sealed envelope, indicating the animal's assignment to 1 of 2 Groups; Group A: saline as placebo $(10 \mathrm{ml}$ dilution bolus $)+$ adrenaline $(0.02 \mathrm{mg} / \mathrm{kg})$. Group B: magnesium sulphate $(0.15 \mathrm{mg} / \mathrm{kg} / 10 \mathrm{ml}$ dilution bolus $)+$ adrenaline $(0.02$ $\mathrm{mg} / \mathrm{kg}$ ). All the investigators were blinded as to the medication used except the principal investigator who did not take part in any experimental procedure.

Ventricular fibrillation (VF) was induced with a 9V ordinary lithium battery as previously described [7] and the animals were left untreated for 5 minutes. Immediately afterwards drugs according to the animal's Group were injected to the marginal auricular vein and resuscitation procedures started with oxygen $\left(\mathrm{FiO}_{2} 100 \%\right)$ and precordial compressions with a mechanical chest compressor (LUCAS ${ }^{\mathrm{TM}}$ Chest Compression System, Jolife AB, Mantzaris, Greece) for 2 minutes. Defibrillation was then attempted with a $4 \mathrm{~J} / \mathrm{kg}$ monophasic waveform shock (PortaPak/90-Medical research laboratories inc., Greece). If the cardiac rhythm was not compatible with a pulse, precordial compression was resumed for $2 \mathrm{~min}$. Successful resuscitation was defined as the return of spontaneous rhythm with a MAP of at least 60 $\mathrm{mmHg}$ for a minimum of $5 \mathrm{~min}$.

Endpoints of the experiment were defined as: i) asystole and ii) return of spontaneous circulation (ROSC). The ani- mals who restored spontaneous circulation were monitored for $240 \mathrm{~min}$, while anaesthesia was maintained. After $4 \mathrm{~h}$ of post-resuscitation monitoring, the intravenous infusions of cis-atracurium and propofol were discontinued. All catheters were removed using a surgical technique as previously described [6]. The ventilator was switched off and the animals were ventilated by manual squeezing of the reservoir bag (FiO2 $100 \%$ ). Atropine $0.2 \mathrm{mg} / \mathrm{Kg}$ followed by neostigmine $0.05 \mathrm{mg} / \mathrm{Kg}$ were administered after the first spontaneous swallowing reflex was detected. The animals were extubated after adequate depth of inspiration was ascertained and the $\mathrm{SpO} 2$ measurement was $>97 \%$. Following the appearance of the righting reflex, each animal was returned to its enclosure. Each parameter of neurological alertness [8] of the surviving animals was scored $48 \mathrm{~h}$ after ROSC. After the final measurements were completed, the animals were euthanatised by a fatal overdose of thiopental.

Blood samples were collected at 60,120 and $240 \mathrm{~min}$ in the post-resuscitation phase in order to measure NSE and S100.The blood was then centrifuged at $3000 \mathrm{rpm}$ for $10 \mathrm{~min}$ and the serum was stored in liquid nitrogen at $-70^{\circ} \mathrm{C}$. The assessment of S-100 and NSE serum concentrations was performed by an immunolumi-nometric assay, using a LIAISON analyser (LIAISON Sangtec $100^{\mathrm{R}}$, Manufacturer.AB Sangtec Medical, P.O. Box 20045, S-16102BROMMA). All assays were performed in a blinded manner. The total number of ventricular ectopic beats was counted over an interval of $30 \mathrm{~min}$ after successful resuscitation as previously described [9].

Measured and derived haemodynamic data over time were analysed, using SPSS 13.0 for Windows. One-sample Kolmogorov-Smirnov $\mathrm{Z}$ tests were used to test whether variables within each group are normally distributed. As none of the variables were found to be normally distributed, MannWhitney $U$ tests were used in order to test whether the two groups were significantly different at each stage of the experiment. Outcome differences between each sample were analysed with the use of paired t-test. On all tests, $\mathrm{p}$ values $<0.05$ were considered statistically significant.

\section{RESULTS}

Baseline haemodynamic measurements did not differ between the two groups, as shown in Table 1. By the end of the $5^{\text {th }}$ minute of VF, MAP decreased from $89.3 \pm 7.6 \mathrm{mmHg}$

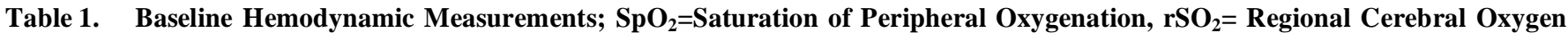
Saturation

\begin{tabular}{|c|c|c|c|}
\hline & Group A & Group B & $\mathbf{P}$ \\
\hline Systolic Blood Pressure (mmHg) & $104.3 \pm 8.0$ & $110.4 \pm 18.3$ & NS \\
\hline Diastolic Blood Pressure $(\mathrm{mmHg})$ & $77.6 \pm 11.6$ & $86.0 \pm 13.7$ & NS \\
\hline Mean Arterial Pressure (mmHg) & $89.3 \pm 7.6$ & $94.9 \pm 8.8$ & NS \\
\hline $\mathrm{SpO}_{2}(\%)$ & $91.1 \pm 3.9$ & $94.0 \pm 1.9$ & NS \\
\hline Coronary Perfusion Pressure (mmHg) & $67.2 \pm 11.1$ & $76.9 \pm 14.5$ & NS \\
\hline $\mathrm{rSO}_{2}(\%)$ & $61.1 \pm 2.5$ & $61.2 \pm 2.0$ & NS \\
\hline
\end{tabular}


Table 2. Post-Resuscitation Dysrhythmias; PVC = Premature Ventricular Contractions, VT = Ventricular Tachycardia

\begin{tabular}{|c|c|c|c|}
\hline & PVC & Salvos & Episodes of VT \\
\hline \hline Group A & $76 \pm 25$ & $16 \pm 4$ & $22 \pm 7$ \\
\hline Group B & $24 \pm 23$ & $8 \pm 5$ & $8 \pm 2$ \\
\hline P & $<0.05$ & $<0.05$ & $<0.05$ \\
\hline
\end{tabular}

to $22.5 \pm 3.3 \mathrm{mmHg}$ in group $\mathrm{A}$, and from $94.9 \pm 8.8 \mathrm{mmHg}$ to $21.8 \pm 2.4 \mathrm{mmHg}$ in Group B ( $\mathrm{p}=\mathrm{NS})$. CPP declined rapidly and remained between 0 and $3 \mathrm{mmHg}$ in both Groups.

All animals, but one in Group A, were succesfully resuscitated. The deceased animal was excluded from further statistical analysis. Just before the first defibrillation attempt, no significant differences in haemodynamic parameters between the 2 groups were observed. However, there was a trend toward lower aortic systolic pressure (Group A: 76.5 \pm 13.0 , Group B: 70.9 \pm 11.3 ), aortic diastolic pressure (Group A: $36.5 \pm 4.5$, Group B: $31.2 \pm 6.8$ ) and CPP (Group A:

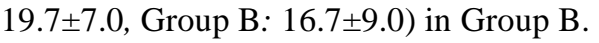

All animals were monitored for 4 hours. Postresuscitation heart rate, blood pressures and right atrial pressure of both groups did not differ significantly during the whole post-resuscitation phase. However, ventricular ectopy was minimized in Group B, as shown in Table 2. $\mathrm{rSO}_{2}$ values in Group B were significantly higher at the $2^{\text {nd }}$ min of CPR and remained significantly higher during the first $5 \mathrm{~min}$ of ROSC (Fig. 1). S-100 and NSE values increased significantly in all resuscitated animals in the observation phase. However, S-100 and NSE values in Group B were statistically lower than those measured in Group A during the whole post-resuscitation period (Fig. 2, 3). Furthermore, a significant negative correlation was found between $\mathrm{rSO}_{2}$ and S-100 ( $\mathrm{r}=-0.71, \mathrm{p}<0.05)$ and NSE $(\mathrm{r}=-0.64, \mathrm{p}<0.05)$ respectively, during the whole post-resuscitation phase. Finally, animals in Group B scored higher in a neurological assessment scale than animals in Group A $(p<0.05)($ Fig. 4).

\section{DISCUSSION}

Global interruption of the cerebral circulation causes general brain oedema and selective neuronal death in vulnerable areas of the brain, whereas a period of extended anoxia time leads to infarction in the cortical and subcortical regions $[2,10]$. Meanwhile, ischaemic reperfusion injury in patients resuscitated after $\mathrm{CA}$ is known to damage organs subsequently, as neutrophils, activated by proinflammatory cytokines, infiltrate visceral interstitial spaces and occasionally damage visceral tissues and cells [11-13]. It is thus conceivable that organ damage by reperfusion injury influences the outcome of resuscitated patients [14]. During cerebral ischaemia, there is also excessive activity of amino acids, especially glutamate. When the glutamate receptors are activated, the intracellular calcium increases. This leads to activation of intracellular enzymes and neuronal death [15].

NSE is a dimer intracellular enzyme of glucose metabolism and occurs as $\gamma \gamma$-enolase in neurons and as $\alpha \gamma$-enolase in neuroendocrine cells and in small lung cancer cells [16]. Several authors have demonstrated that different cerebral diseases such as ischaemic stroke, meningoencephalitis and head injury cause an elevation in the serum concentration of NSE $[17,18]$. Measurement of NSE may supplement clinical cerebral assessment after CA and successful resuscitation [19]. Even though its prognostic value in the assessment of comatose patients recovering from $\mathrm{CA}$ is still under debate, several studies have concluded that a NSE rise usually occurs early in victims of CA.

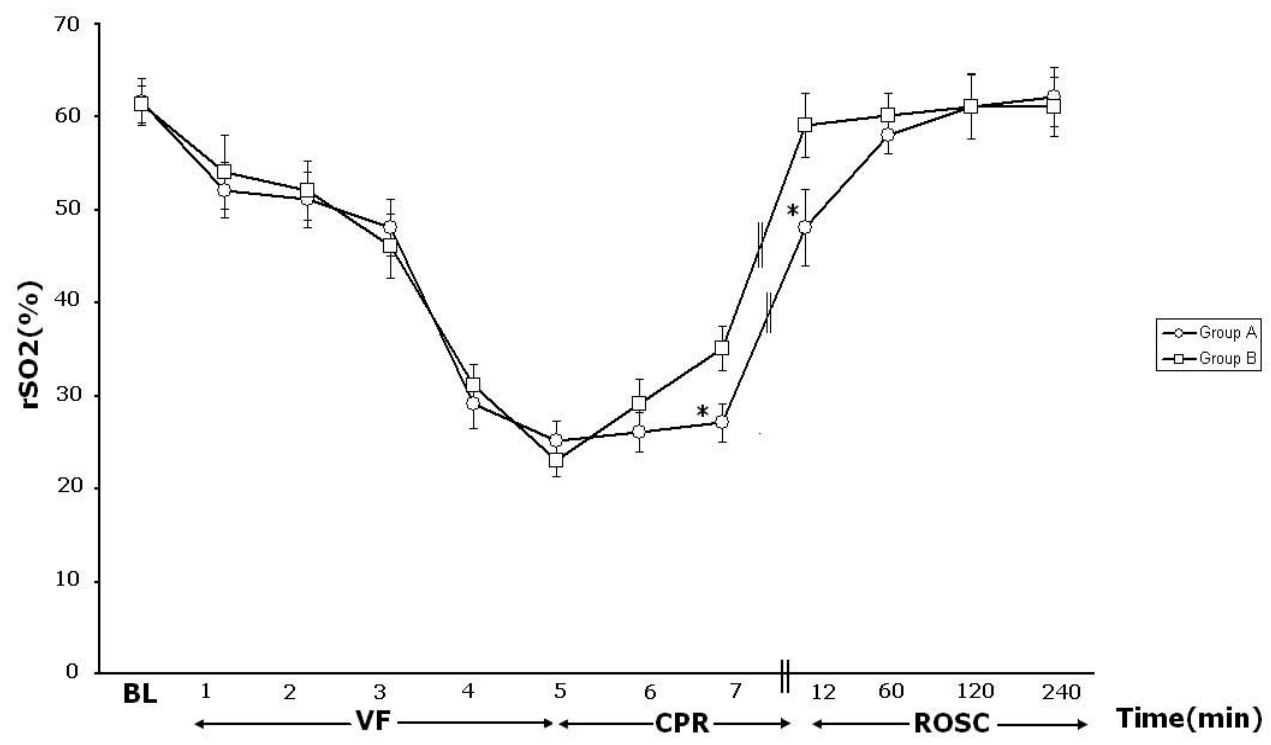

Fig. (1). $\mathrm{rSO}_{2}$ fluctuation during the experiment. ${ }^{*}=\mathrm{p}<0.05$ Group A versus Group $\mathrm{B}$. $\mathrm{VF}=$ ventricular fibrillation, $\mathrm{CPR}=$ cardiopulmonary resuscitation, $\mathrm{rSO}_{2}=$ regional cerebral oxygen saturation . 


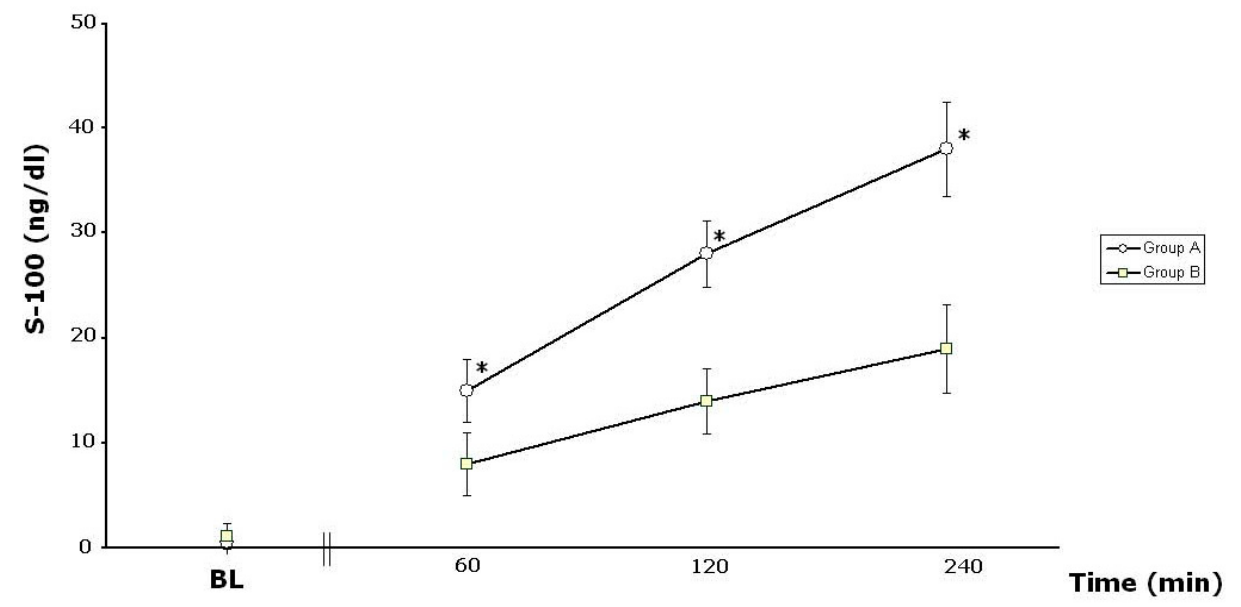

Fig. (2). S-100 fluctuation in time. ${ }^{*}=p<0.05$ Group A versus Group B. BL=baseline.

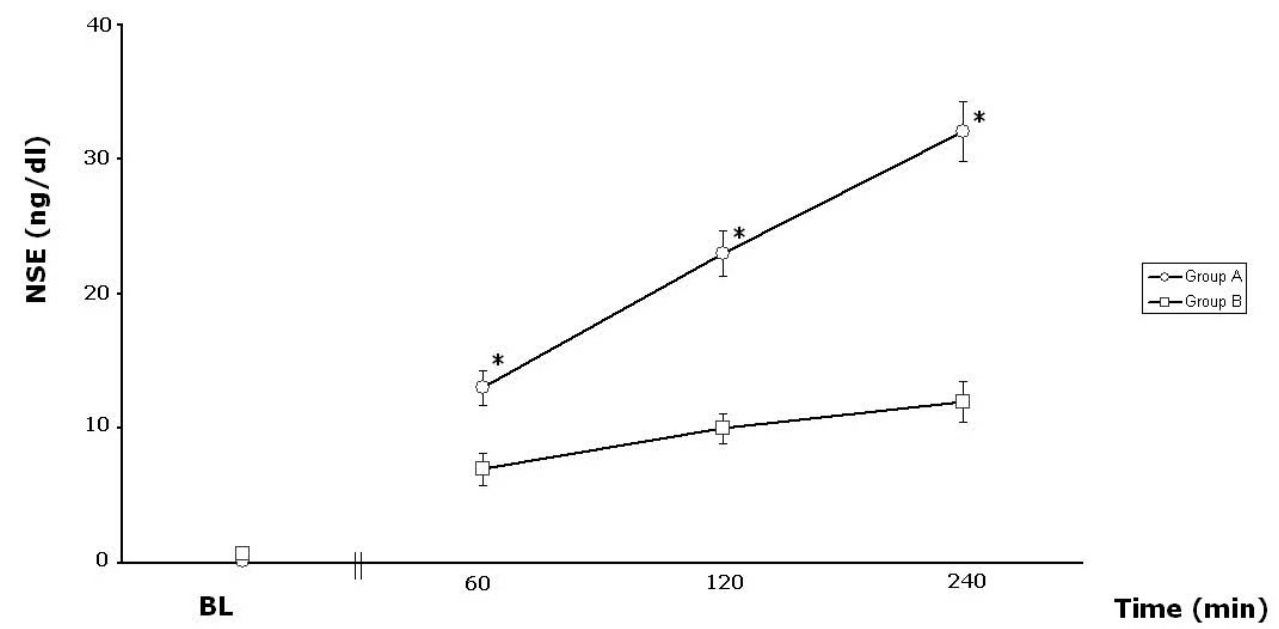

Fig. (3). NSE fluctuation in time. ${ }^{*}=p<0.05$ Group A versus Group B. BL=baseline.

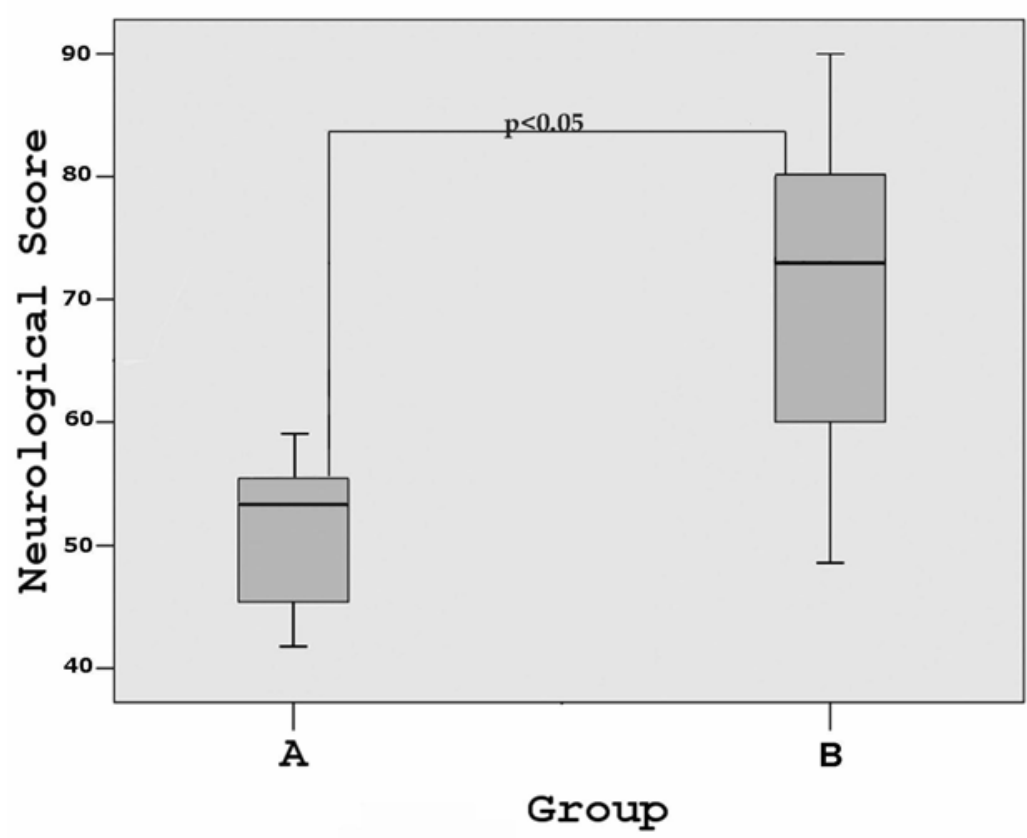

Fig. (4). Neurological alertness score in both Groups. 
S-100 is a dimer intracellular calcium-binding protein with the heterodimer S-100a occurring in melanocytes and glia cells and the homodimer S-100b in glia and Schwann's cells [20]. Elevated serum levels of S-100 have been observed after ischaemic stroke, meningoencephalitis and head injury. Several clinical studies have shown that increased serum concentrations of protein S-100 predict ischaemic brain damage after cardiac surgery. S-100 may also be released from the heart or other injured tissue, indicating that S-100 has a heterogeneous cerebral and extracerebral release pattern [21]. The implication of the protein in CA patients has been recently pointed out, as a rise in S-100 indicated severe cerebral damage and poor neurological recovery [22]. Our study has confirmed that NSE and S-100 rise occur early in the post-resuscitation phase and continue to rise 4 hours after CA.

NIRS is a non-invasive and easily applicable technique that might help to prognosticate outcome and offers new insights into monitoring cerebral oxygenation after CA. A clinical study by Mullner et al. has shown that low $\mathrm{rSO}_{2}$ readings after CA are associated with a higher mortality [23]. In another clinical study, $\mathrm{rSO}_{2}$ appears to be correlated to electroencephalogram (EEG), in patients undergoing surgery for cardioverter-defibrillator implantation. When circulatory arrest occurred, $\mathrm{rSO}_{2}$ measurements decreased rapidly, following the changes of the EEG waveform. After recovering from circulatory arrest, EEG waveform normalized and $\mathrm{rSO}_{2}$ turned to baseline values [24]. In addition, Shahand et al. concluded from their study in volunteers that $\mathrm{rSO}_{2}$ may serve as a reliable indicator of changes in brain oxygenation induced by hypoxaemia [25]. Furthermore, there is great evidence that the use of NIRS is essential to detect malperfusion of the frontal lobes of the cerebral hemispheres [26]. These are in accordance with our findings, where $\mathrm{rSO}_{2}$ values decreased rapidly in the course of VF and rose during CPR, reaching baseline values early in the post-resuscitation phase.

Magnesium has a voltage-gated antagonist action on the $\mathrm{N}$-methyl-D-aspartate (NMDA) receptor. Interest has focused on the role of NMDA receptor antagonists in the protection of the central nervous system from ischaemic damage [27]. There has been keen interest in the use of magnesium as a potential neuroprotective intervention. In a study in newborn piglets, magnesium preserved NMDA receptor binding properties and maintained ionic homeostasis by attenuating the reduction in $\mathrm{Na}^{+} / \mathrm{K}^{+}$-ATPase activity [28].

Furthermore, administration of magnesium to newborn piglets prevented hypoxia-induced modification of neuronal nuclear membrane function that leads to intranuclear $\mathrm{Ca}^{2+}$ dependent transcription of apoptotic proteins leading to hypoxic neuronal programmed cell death [29].

According to a systematic review of currently available pharmacological neuroprotective agents in CA, the use of magnesium seems to be effective in global and focal cerebral ischaemia, both in animal studies and in clinical trials. Amighi et al. investigated the prognostic impact of magnesium serum levels with respect to the occurrence of neurological events in patients with advanced atherosclerosis and found that low magnesium serum levels indicate an increased risk for neurological events in patients with symptomatic peripheral artery disease [30]. Also, magnesium ther- apy might be efficient as a prophylactic adjacent therapy in acute lacunar stroke syndrome and after aneurismal subarachnoid haemorrhage to reduce the risk for poor outcome $[31,32]$. Moreover, several animal studies have demonstrated a protective effect of magnesium in focal ischaemia after temporary or permanent cerebral artery occlusion [33, 34]. In a trial of Lee et al. male rats (Sprague-Dawley) were subjected to right middle cerebral artery occlusion for 90 minutes followed by 72 hours of reperfusion. Administration of magnesium at the commencement of reperfusion enhanced electrophysiological and neurobehavioural recovery and reduced brain infarction after cerebral ischaemiareperfusion [35]. This is in agreement with our study that demonstrated that magnesium may have some neuroprotective effect following $\mathrm{CA}$, as indicated by biochemical markers of cerebral ischaemia, supported further by $\mathrm{rSO}_{2}$ values and by the neurological alertness score.

There are some studies that question routine use of magnesium in resuscitation. In the study of Thel et al. there was no improvement in survival or hospital discharge in patients with in-hospital cardiac arrest who were treated with magnesium supplementation compared to placebo. However, if the quality of life in survivors was specified as the primary endpoint, this trial would have had a positive result, which suggests that magnesium may have a protective cerebral effect [36]. Regarding out-of-hospital CA, 3 randomized studies failed to prove any beneficial outcome in survival and/or neurological outcome in patients who received magnesium sulphate [37-39]. However, in these studies the quality of chest compressions was not standardized adding a significant bias in their results. The use of magnesium has not been proven to exert any marked effects on diastolic aortic pressure and CPP [40]. This was further confirmed by this experimental model where no significant difference was marked with the addition of magnesium.

Furthermore, magnesium has been safely applied to patients with a compromised left ventricular pump function [41]. In addition, it has been shown to act favourably against a number of ventricular arrhythmias [38]. Several studies have also shown that an infusion of magnesium can reduce the incidence of arrhythmias occurring after acute myocardial infarction [42]. This swine experimental model demonstrated that the incidence of ventricular ectopy was significantly lower in the magnesium-treated group.

The authors recognise several limitations in this preliminary experimental study. The number of animals is relatively small, and the experiment was conducted on apparently healthy pigs. Furthermore, in this experimental model, no neurological deficit score was assessed, and the ischaemic cerebral damage was mainly based on indirect markers and measurements.

Within these limitations, the authors conclude that magnesium may exert neuroprotective effects in cerebral ischaemia, caused by CA. However, more research is essential to further clarify the potential beneficial effects of magnesium.

\section{CONCLUSIONS}

Magnesium sulphate, when administered during CPR, does not adversely affect ROSC, minimizes ventricular ectopic beats, increases $\mathrm{rSO} 2$ values and exerts some neuroprotective effect as evidenced by decreased values of ischaemia 
cerebral markers and by the improved neurological alertness score in this swine model of CA.

\section{LIST OF ABBREVIATIONS}

$\mathrm{CA}=$ Cardiac Arrest
$\mathrm{NSE}=$ Neuron Specific Enolase
$\mathrm{S}-100=$ protein soluble in $100 \%$ ammonium sulphate
$\mathrm{CPR}=$ Cardiopulmonary Resuscitation
$\mathrm{ECG}=$ Electrocardiogram
$\mathrm{SpO}_{2}=$ Pulse Oximetry
$\mathrm{NIRS}=$ Near Infrared Spectroscopy
$\mathrm{rSO}_{2}=$ Regional Cerebral Oxygen Saturation
$\mathrm{MAP}=$ Mean Arterial Pressure
$\mathrm{CPP}=$ Coronary Perfussion Pressure
$\mathrm{VF}=$ Ventricular Fibrillation
$\mathrm{ROSC}=$ Return of Spontaneous Circulation
$\mathrm{EEG}=$ Electroengephalogram
$\mathrm{NMDA}=$ N-methyl-D-aspartate

\section{REFERENCES}

[1] Sans S, Kesteloot H, Kromhout D. The burden of cardiovascular diseases mortality in Europe. Task force of the European society of cardiology on cardiovascular mortality and morbidity statistics in europe. Eur Heart J 1997; 18: 1231-48.

[2] Ekmektzoglou K, Xanthos T, Papadimitriou L. Biochemical markers (NSE, S-100, IL-8) as predictors of neurological outcome in patients after cardiac arrest and return of spontaneous circulation. Resuscitation 2007; 75: 219-28.

[3] Dubé L, Granry J. The therapeutic use of magnesium in anesthesiology, intensive care and emergency medicine: a review. Can J Anaesth 2003; 50: 732-46.

[4] Fischer EG, Ames A, Lorenzo AV. Cerebral blood flow immediately following brief circulation stasis. Stroke 1979; 10: 423-7.

[5] Xanthos T, Lelovas P, Vlachos I, et al. Cardiopulmonary arrest and resuscitation in Landrace/Large White swine: a research model. Lab Anim 2007; 41: 353-62.

[6] Xanthos T, Bassiakou E, Koudouna E, et al. Baseline hemodynamics in anesthetized landrace-large white swine: reference values for research in cardiac arrest and cardiopulmonary resuscitation models. J Am Assoc Lab Anim Sci 2007; 46: 21-5.

[7] Koudouna E, Xanthos T, Bassiakou E, et al. Levosimendan improves the initial outcome of cardiopulmonary resuscitation in a swine model of cardiac arrest. Acta Anaesthesiol Scand 2007; 51: 1123-9.

[8] Xanthos T, Bassiakou E, Koudouna E, et al. Combination pharmacotherapy in the treatment of experimental cardiac arrest. Am J Emerg Med 2008 (in press).

[9] Walker MJ, Curtis MJ, Hearse DJ, et al. The lamberth convention: guidelines for the study of arrhythmias in ischemia, infarction and reperfusion. Cardiovasc Res 1988; 22: 447-55.

[10] Safar P, Stezoski W, Nemoto EM. Amelioration of brain damage after 12 minutes cardiac arrest in dogs. Ach Neurol 1976; 33: 91-5.

[11] Auer RN, Benveniste H. Hypoxia and related conditions. In: Graham DI, Lantos FL, Eds. Greenfield's neuropathology. London, Edward Arnold, 1997; pp. 263-314.

[12] Sekido N, Mukaida N, Harada A, et al. Prevention of lung reperfusion injury in rabbits by a monoclonal antibody against interleukin8. Nature 1993; 365: 654-7.

[13] Kitagawa K, Matsumoto M, Oda T, et al. Free radical generation during brief period of cerebral ischemia may trigger delayed neuronal death. Neuroscience 1990; 35: 551-8.

[14] Schwartz AC. Neurological recovery after cardiac arrest. Am J Emerg Med 1985; 3: 1-10.

[15] Lyden P, Wahlgren NG. Mechanisms of action of neuroprotectants in stroke. J Stroke Cardiovasc Dis 2000; 9: 9-14.
[16] Pahlman S, Esscher T, Bergvall P, et al. Purification and characterization of human neuron-specific enolase: radioimmunoassay development. Tumour Biol 1984; 5: 127-39.

[17] Missler U, Wiesmann M, Friedrich C, et al. S-100 protein and neuron-specific enolase concentrations in blood as indicators of infarction volume and prognosis in acute ischemic stroke. Stroke 1997; 28: 1956-60.

[18] Fassbender K, Schmidt R, Schreiner A, et al. Leakage of brainoriginated proteins in peripheral blood: temporal profile and diagnostic value in early ischemic stroke. J Neurol Sci 1997; 148: 101-5.

[19] Martens P. Serum neuron-specific enolase as a prognostic marker for irreversible brain damage in comatose cardiac arrest survivors. Acad Emerg Med 1996; 3: 126-31.

[20] Schafer BW, Heizmann CW. The S100 family of EF-hand calciumbinding proteins: functions and pathology. Trends Biochem Sci 1996; 21: 134-40.

[21] Snyder-Ramos SA, Gruhlke T, Bauer H, et al. Cerebral and extracerebral release of protein $\mathrm{S} 100 \mathrm{~B}$ in cardiac surgical patients. Anaesthesia 2004; 59: 344-9.

[22] Hachimi-Idrissi S, Van der Auwera M, Schiettecatte J, et al. S-100 protein as early predictor of regaining consciousness after out of hospital cardiac arrest. Resuscitation 2002; 53: 251-7.

[23] Mullner M, Sterz F, Bimder M, et al. Near infrared spectroscopy during and after cardiac arrest-preliminary results. Clin Intensive Care 1995; 6: 107-11.

[24] de Vries JW, Visser GH, Bakker PF. Neuromonitoring in defibrillation threshold testing. A comparison between EEG, near-infrared spectroscopy and jugular bulb oximetry. J Clin Monit 1997; 13: 303-7.

[25] Shah N, Trivedi NK, Clack SL, et al. Impact of hypoxemia on the performance of cerebral oximeter in volunteer subjects. J Neurosurg Anesthesiol 2000; 12: 201-9.

[26] Orihashi K, Sueda T, Okada K, et al. Near-infrared spectroscopy for monitoring cerebral ischemia during selective cerebral perfusion. Eur J Cardiothorac Surg 2004; 26: 907-11.

[27] Fawcett WJ, Haxby EJ , Male DA. Magnesium: physiology and pharmacology. Br J Anaesth 1999; 83: 302-20.

[28] Hoffman DJ, Marro PJ, McGowan JE, et al. Protective effect of $\mathrm{MgSO} 4$ infusion on NMDA receptor binding characteristics during cerebral cortical hypoxia in the newborn piglet. Brain Res 1994; 644: 144-9.

[29] Mami AG, Ballesteros J, Mishra OP, et al. Effects of magnesium sulphate administration during hypoxia on $\mathrm{Ca} 2$ influx and IP3 receptor modification in cerebral cortical neuronal nuclei of newborn piglets. Neurochem Res 2006; 31: 63-70.

[30] Amighi J, Sabeti S, Schlager O, et al. Low serum magnesium predicts neurological events in patients with advanced atherosclerosis. Stroke 2004; 35: 22-7.

[31] Aslanyan S, Weir CJ, Muir KW, Lees KR. Magnesium for treatment of acute lacunar stroke syndromes, further analysis of the IMAGES trial. Stroke 2007; 38: 1269-73.

[32] Muroi C, Terzic A, Fortunati M, Yonekawa Y, Keller E. Magnesium sulfate in the management of patients with aneurysmal subarachnoid hemorrhage: a randomized, placebo-controlled, doseadapted trial. Surg Neurol 2008; 69: 33-9.

[33] Marinov MB, Harbaugh KS, Hoopes PJ, et al. Neuroprotective effects of preischemia intraarterial magnesium sulfate in reversible focal cerebral ischemia. J Neurosurg 1996; 85: 117-24.

[34] Yang Y, Li Q, Ahmad F, et al. Survival and histological evaluation of therapeutic window of post-ischemia treatment with magnesium sulfate in embolic stroke model of rat. Neurosci Lett 2000; 285: 119-22.

[35] Lee EJ, Lee MY, Chang GL, et al. Delayed treatment with magnesium: reduction of brain infarction and improvement of electrophysiological recovery following transient focal cerebral ischemia in rats. J Neurosurg 2005; 102: 1085-93.

[36] Thel MC, Armstrong AL, McNulty SE, et al. Randomised trial of magnesium in in-hospital cardiac arrest. Lancet 1997; 350: 1272-6.

[37] Fatovich DM, Prentice DA, Dobb GJ. Magnesium in cardiac arrest (the magic trial). Resuscitation 1997; 35: 237-41.

[38] Hassan TB, Jagger C, Barnett DB. A randomized trial to investigate the efficacy of magnesium sulphate for refractory ventricular fibrillation. Emerg Med J 2002; 19: 57-62. 
[39] Miller B, Craddock L, Hoffenberg S, et al. Pilot study of intravenous magnesium sulfate in refractory cardiac arrest: safety data and recommendations for future studies. Resuscitation 1995; 30: 3-14.

[40] Brown CG, Griffith RF, Neely D, et al. The effect of intravenous magnesium administration on aortic, right atrial and coronary perfusion pressures during CPR in swine. Resuscitation 1993; 26 : $3-12$.
[41] Weigl M, Tenze G, Steinlechner B, et al. A systematic review of currently available pharmacological neuroprotective agents as a sole intervention before anticipated or induced cardiac arrest. Resuscitation 2005; 65: 21-39.

[42] Allegra J, Lavery R, Cody R, et al. Magnesium sulfate in the treatment of refractory ventricular fibrillation in the prehospital setting. Resuscitation 2001; 49: 245-9.

(C) Prapa et al.; Licensee Bentham Open.

This is an open access article licensed under the terms of the Creative Commons Attribution Non-Commercial License (http://creativecommons.org/licenses/by-nc/3.0/) which permits unrestricted, non-commercial use, distribution and reproduction in any medium, provided the work is properly cited. 